ARTIGO ORIGINAL

OPEN ACCESS

\title{
ESCRITÓRIO DE GERENCIAMENTO DE PROJETOS: PROPOSTA PARA UMA EMPRESA DO RAMO INDUSTRIAL DE RODOVIAS E EXTRAÇÃO DE MINÉRIO
}

\author{
PROJECT MANAGEMENT OFFICE: PROPOSAL FOR A COMPANY WITH THE INDUSTRIAL \\ BRANCH OF ROADS AND ORE EXTRACTION
}

\section{$\underline{\text { Samuel Vinicius Bonato }}{ }^{1}$, Fernanda Fagundes Gandin ${ }^{2}, \underline{\text { Luciano Maciel Ribeiro }}{ }^{3}, \&$ Errol Fernando Zepka Pereira Junior ${ }^{4 *}$}

\footnotetext{
123 Universidade Federal do Rio Grande - FURG. ${ }^{4}$ Universidade Federal de Santa Catarina - UFSC.

${ }^{1}$ svbonato@gmail.com ${ }^{2}$ ff.gandin@gmail.com ${ }^{3}$ professor@lucianoribeiro.com.br ${ }^{4 *}$ zepkaef@gmail.com
}

\section{ARTIGO INFO.}

Recebido em: 23.10.2020

Aprovado em: 10.04.2021

Disponibilizado em: $\mathbf{1 8 . 0 6 . 2 0 2 1}$

\section{Palavras-Chave:}

Projetos; Escritório de Gerenciamento de Projetos; Indústria; rodovias; extração de minério.

\section{KEYWORDS:}

Projects; Project Management Office; highways; ore extraction; Project management maturity level.

\section{*Autor Correspondente: Pereira Junior, E. F. Z.}

\section{RESUMO}

A presente pesquisa, tem como objetivo avaliar a situação atual da empresa estudada no que tange ao gerenciamento de projetos e propor um modelo mais adequado para sua estrutura, uma vez que esta organização emprega grande parte de seu orçamento em diversos tipos de projetos e não possui um processo definido para gerenciamento deles. Esta pesquisa foi realizada em uma empresa do ramo industrial, fabricante e revendedora de máquinas para pavimentação de rodovias e extração de minério. Com base na pesquisa, pode-se afirmar que não existe uma fórmula única para implementação nem mesmo um único modelo de escritório de gerenciamento de projetos: cada organização pode desenvolver uma configuração específica, baseado em suas características, recursos e conhecimento. Conclui-se que a implantação de um gerenciamento de projetos adequado à estrutura da empresa, trará benefícios concretos para ela, proporcionando um maior controle sobre os investimentos empregados nos projetos de negócio e disseminando o conhecimento em gerenciamento de projetos na empresa como um todo. Diante da comparação apresentada, foi possível identificar o quanto a empresa perdeu na execução inadequada do segundo projeto, onde o custo ultrapassou em $107 \%$ e o prazo em 48 dias úteis do planejado. Propõe-se que a empresa implemente o escritório de gerenciamento de projetos conforme modelo elaborado nesta pesquisa, cujas características foram baseadas na metodologia MMGP e, realize o acompanhamento das atividades durante o primeiro ano de operação.

\section{ABSTRACT}

The present research. aims to assess the current situation of the company studied with respect to project management and propose a model more suitable for its structure, since this organization uses a large part of its budget in various types of projects and does not have a defined process for managing them. This research was carried out at a company in the industrial sector, manufacturer, and dealer of machinery for paving roads and mining ore. Based on the research, it can be said that there is no single formula for implementation or even a single model of PE: each organization can develop a specific configuration, based on its characteristics, resources and knowledge. It is concluded that the implementation of a Project Management Office appropriate to the structure of the company, will bring concrete benefits for it, providing greater control over the investments employed in business projects and disseminating knowledge in project management across the company. In view of the comparison presented, it was possible to identify how much the company lost in the inadequate execution of the second project, where the cost exceeded $107 \%$ and the term in 48 working days of the planned. It is proposed that the company implements the Project Management Office according to the model elaborated in this research, whose characteristics were based on the MMGP methodology and, follow up the activities during the first year of operation. 

uma empresa do ramo industrial de rodovias e extração de minério. Brazilian Journal of Production Engineering, 7(2), 111-127.

\section{INTRODUÇão}

Diante de um cenário altamente competitivo as empresas que desejam manter-se no mercado e expandir seus negócios precisam buscar estratégias que as diferenciem de seus concorrentes ou que aumentem o desempenho de seus processos, diminuam o desperdício de seus recursos, controlem melhor a aplicação e possibilitem uma maior visibilidade do retorno financeiro sobre seus investimentos. Além de estratégias de negócio, muitas empresas já vêm adotando a metodologia de gerenciamento de projetos como aliada para o desenvolvimento de seus negócios. No entanto, a utilização da metodologia exige uma mudança cultural na organização e a formalização do gerenciamento de projetos como um processo de negócio na empresa.

Nesse contexto, surge a necessidade de aprimorar ferramentas, habilidades e técnicas, além de novas alternativas e tentativas de superar esses desafios, assim, o gerenciamento de projetos aparece como um importante instrumento de desenvolvimento e mudança organizacional (Alves et al., 2013) e uma maneira de atingir os objetivos estratégicos das organizações (Lucca et al., 2020).

Como explicado por Siqueira et al. (2017), cultura organizacional, estilo e estrutura são fatores que influenciam a tomada de decisão (Pantoja et al., 2020) e como os projetos são priorizados, planejados e executados (Kerzner, 2006). Nesse contexto, é importante destacar o papel do PMO (Escritório de Gerenciamento de Projetos) ou escritório de projetos, principalmente em uma estrutura orientada a projetos.

Empresas de todo o mundo, em diferentes setores, aderiram cada vez mais ao escritório do projeto. O gerenciamento de projetos nas organizações, no entanto, cresce constantemente, principalmente considerando as altas taxas de falhas nos projetos (Rego \& Silva, 2011; Coimbra et al., 2019), bem como a estrutura de muitas empresas que não estão preparadas para lidar com ambientes turbulentos, com a escassez de recursos. e projetos cada vez mais numerosos e complexos (Aubry et al., 2007).

Portanto, mostra-se a necessidade de centralizar o controle, os recursos, as informações e o gerenciamento em uma unidade mais formal, trazendo o Escritório de Gerenciamento de Projetos (PMO) como uma estrutura capaz de atender a essa necessidade (Lucca et al., 2020).

Diante desse cenário, a presente pesquisa. tem como objetivo avaliar a situação atual da empresa no que tange ao gerenciamento de projetos e propor um modelo de gerenciamento de projetos mais adequado para sua estrutura, uma vez que esta organização emprega grande parte de seu orçamento em diversos tipos de projetos e não possui um processo definido para gerenciamento deles. Esta pesquisa foi realizada em uma empresa do ramo industrial, situada na cidade de Porto Alegre, fabricante e revendedora de máquinas para pavimentação de rodovias e extração de minério.

\section{FUNDAMENTAÇÃo TEÓRICA}

\subsection{Projetos}

Grande parte do trabalho realizado em uma organização pode ser definido como trabalho operacional ou projeto, onde o trabalho operacional é contínuo e o projeto possui um fim (Mulcahy, 2009). Ao longo dos anos, os projetos foram tomando dimensões importantes e se 
Citação (APA): Bonato, S. V., Gandin, F. F., Ribeiro, L. M., \& Pereira Junior, E. F. Z. (2021). Escritório de gerenciamento de projetos: proposta para uma empresa do ramo industrial de rodovias e extração de minério. Brazilian Journal of Production Engineering, 7(2), 111-127.

tornaram um instrumento fundamental no desenvolvimento das organizações. As principais mudanças organizacionais, em nível de vantagens competitivas, têm sido executadas através de projetos organizacionais (Campos et al., 2020).

O projeto é um esforço temporário, com início e término bem definidos, que é estabelecido para criar um produto, serviço ou um resultado exclusivo. Um projeto é encerrado quando os seus objetivos forem atingidos ou ainda, quando se detectar que estes objetivos não poderão ou não serão atingidos, ou até mesmo, quando ele não for mais necessário (PMI, 2017). De acordo com Irfan et al. (2019), um projeto pode ser tratado como uma série de tarefas que tem objetivos específicos, respeita restrições específicas, possui data de início e fim bem definidos, possui limites financeiros, consome recursos humanos ou não e, são multifuncionais.

Projetos são utilizados frequentemente como meio de atingir os objetivos estratégicos de uma organização e, portanto, os objetivos do projeto devem estar alinhados aos objetivos estratégicos da empresa. Estes objetivos, além de alinhados à estratégia, devem ser de conhecimentos de todos os envolvidos (Irfan et al., 2019). Conforme Evers e Chappin (2020), os projetos são a forma de responder a desafios que não podem ser atendidos através da operação normal de uma empresa, podem envolver um setor, toda a organização ou até mesmo outras empresas, consórcios e parcerias.

Os projetos são compostos por uma rede de atividades que abrangem diversas ações, que por sua vez compõem uma cadeia de atividades sucessoras e predecessoras. Normalmente, as atividades de um projeto são agrupadas em fases que, em conjunto, dão origem ao ciclo de vida do projeto. Conforme Mota (2019), o ciclo de vida varia de organização para organização, de acordo com cada especificidade, no entanto, o ciclo de vida de um projeto geralmente é composto por cinco fases, a saber: (i) projeto conceitual: identificação da necessidade do projeto, origem do projeto; (ii) desenvolvimento avançado: fase de planejamento e orçamentação do projeto; (iii) projeto detalhado: fase onde é executado o detalhamento do projeto. ocorre após a aprovação do projeto; (iv) produção: consiste na própria execução do que foi planejado; e (v) término: encerramento do projeto, última fase.

A influência das partes interessadas, os riscos e as incertezas são maiores durante a fase inicial e caem ao longo da vida do projeto, assim como, os custos das mudanças e correções de erros geralmente aumentam significativamente conforme o projeto vai se encaminhado para o seu término. Segundo PMI (2017), um projeto termina quando pelo menos uma das alternativas abaixo for verdadeira: (i) os objetivos foram alcançados; (ii) fica claro que os objetivos não serão ou não poderão ser atingidos; ou (iii) não existe mais a necessidade do projeto.

\subsection{GeSTão de Projetos}

Uma empresa que pratica uma boa autogestão, possui objetivos estratégicos bem definidos, avalia as opções para alcançá-los e conduz a análise financeira para determinar os projetos que alcançarão os objetivos com menor dispêndio de custo, tempo e recursos de pessoal. Este é o processo correto para determinar a execução de um projeto (Mulcahy, 2009).

Assim como as demais operações da empresa, os projetos também necessitam de gerenciamento como forma de alcançarem os objetivos propostos. Através da implantação de metodologias

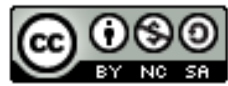


Citação (APA): Bonato, S. V., Gandin, F. F., Ribeiro, L. M., \& Pereira Junior, E. F. Z. (2021). Escritório de gerenciamento de projetos: proposta para uma empresa do ramo industrial de rodovias e extração de minério. Brazilian Journal of Production Engineering, 7(2), 111-127.

para o gerenciamento dos projetos, as organizações podem minimizar os riscos para a realização de seus investimentos (Mota, 2019).

Conforme PMI (2017), "o gerenciamento de projetos é a aplicação de conhecimentos, habilidades, ferramentas e técnicas às atividades do projeto, a fim de atender aos seus requisitos". Nesse sentido, gerenciar um projeto requer a identificação de seus requisitos, adaptação e alinhamento das necessidades das partes interessadas durante o andamento do projeto, além do balanceamento entre as relações conflitantes das áreas de conhecimento da gestão de projetos. As áreas de conhecimento na gestão de projetos possuem uma forte relação entre si, de forma que, se algum fator for modificado em uma das áreas de conhecimento, pelo menos uma outra área será afetada. Uma equipe de projeto deve ser capaz de avaliar as situações e equilibrar as demandas, entregando ao final, um projeto bem-sucedido (PMI, 2017).

Nesse sentido, para Mulcahy (2009), gerenciar projetos corresponde a um processo bem definido, que inclui: iniciação do projeto (iniciar), planejamento do projeto (planejar), execução do projeto (fazer), monitoramento e controle do projeto (verificar e agir) e o encerramento do projeto (terminar). Em um projeto pequeno, esta pode ser exatamente a sequência de execução das atividades, no entanto, grandes projetos podem ser divididos em fases, onde este processo será repetido diversas vezes.

Compreender e seguir o fluxo do processo é extremamente importante para o sucesso do projeto, uma vez que o projeto foi criado para atender um objetivo e o resultado do processo conduz a este objetivo (Longaray et al., 2018). Nesse sentido, Alkhateri et al. (2020) explicam que a primeira obrigação e contínua responsabilidade de um gestor é empenhar-se em obter os melhores resultados econômicos dos recursos empregados ou disponibilizados no momento.

Com relação aos projetos, estes são gerenciados pela figura do gerente de projeto, que por sua vez, deve entender claramente os objetivos estratégicos do projeto para o qual foi designado. Deve ter em mente os objetivos tangíveis e intangíveis ao planejar e gerenciar o projeto, caso contrário, este pode ser concluído dentro dos prazos estabelecidos, atendendo o planejamento de custos, porém fracassar, por não alcançar os objetivos estratégicos para o qual foi iniciado (Mulcahy, 2009).

Para Pereira Junior et al. (2019), são as pessoas que executam o trabalho, e é fundamental que façam da melhor maneira possível. Desta forma, as competências comportamentais e contextuais são igualmente importantes. Aspectos de relacionamento humano afetam todos os envolvidos nos projetos, visto que inúmeros conflitos negativos diários acabam prejudicando a empresa de alguma forma. Estes conflitos podem ser evitados pelo conhecimento destes aspectos por parte do gerente de projeto. Conforme apontado por Pereira Junior et al. (2020), além do aspecto comportamental, o gerente de projetos deve conhecer aspectos financeiros, legais, a organização onde trabalha e outras organizações que possam afetar o seu projeto. Ainda para os autores, esse engajamento se torna ainda mais necessário onde possa haver qualquer barreira e resistência à mudança, pois o envolvimento dos funcionários pode ser decisivo para a eficácia da implementação de uma mudança.

Para o PMI (2017), além de todas as habilidades da área específica, das proficiências e competências do gerenciamento em geral, o gerenciamento de projetos eficaz requer que os 
Citação (APA): Bonato, S. V., Gandin, F. F., Ribeiro, L. M., \& Pereira Junior, E. F. Z. (2021). Escritório de gerenciamento de projetos: proposta para uma empresa do ramo industrial de rodovias e extração de minério. Brazilian Journal of Production Engineering, 7(2), 111-127.

gerentes tenham as seguintes características, a saber: (i) conhecimento: conhecimentos ligados ao gerenciamento de projetos; (ii) desempenho: refere-se ao quanto o gerente de projetos é capaz de realizar aplicando seu conhecimento em gerenciamento de projetos; e (iii) pessoal: refere-se ao comportamento do gerente de projetos enquanto conduz o projeto ou alguma atividade relacionada. Trata da capacidade de orientar a equipe ao mesmo tempo em que atinge o objetivo do projeto.

A estrutura organizacional é um fator ambiental extremamente influenciador na disponibilidade dos recursos da empresa e na forma com que os projetos são conduzidos. As estruturas organizacionais variam de funcionais a projetizadas, com diversas estruturas matriciais entre elas (PMI, 2017).

Para Mulcahy (2009), projetos são influenciados pelas normas culturais, pelas políticas de gerenciamento e pelos procedimentos da organização a qual faz parte, no entanto, os projetos também causam impacto nestes itens, portanto, os melhores gerentes de projeto devem identificar estas influências e gerenciá-las, para beneficiar o projeto e a organização, portanto, conhecer a forma de organização da empresa é fundamental, pois de acordo com esta organização o gerente poderá identificar como as comunicações devem ser feitas e administradas, como e com quem negociar os recursos, entre outros componentes do gerenciamento de projetos.

Mulcahy (2009) ainda define que as estruturas organizacionais podem ser estabelecidas de acordo com o nível de autoridade do gerente de projetos. Abaixo são descritas as estruturas organizacionais do ponto de vista do gerenciamento de projetos: (i) Organização Funcional: é a forma mais comum de organização, é agrupada por áreas de diferentes especializações, tais como, contabilidade, controladoria, fabricação, entre outros. Em geral os projetos ocorrem em um departamento, havendo necessidade de informações ou recursos de outras áreas, a solicitação é transmitida ao seu responsável. Normalmente os membros da equipe fazem as atividades do projeto, além de suas atividades normais do departamento ao qual estão alocados; (ii) Organização Projetizada: este tipo é organizado por projetos.

Ainda em Mulcahy (2009), o gerente de projetos detém o poder sobre os projetos e os recursos são designados e ficam subordinados a ele. Os membros da equipe de projetos fazem as atividades do projeto e quando este é encerrado, não tem um departamento para serem alocados, portanto, precisam ser designados para outro projeto; e (iii) Organização Matricial: este tipo de organização tem como objetivo maximizar os benefícios da organização funcional e por projetos (projetizada). Os membros da equipe se reportam a dois chefes, o gerente de projetos e o gerente funcional. Os membros da equipe fazem o trabalho do projeto, além das atividades funcionais do departamento.

\subsection{Maturidade em Gestão de Projetos}

Conforme Campos et al. (2020), o conceito de maturidade, quando aplicado a uma organização, refere-se ao estado em que a organização se encontra para alcançar seus objetivos. Maturidade em projetos também pode significar que uma organização está perfeitamente condicionada para gerenciar seus projetos.

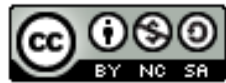


Citação (APA): Bonato, S. V., Gandin, F. F., Ribeiro, L. M., \& Pereira Junior, E. F. Z. (2021). Escritório de gerenciamento de projetos: proposta para uma empresa do ramo industrial de rodovias e extração de minério. Brazilian Journal of Production Engineering, 7(2), 111-127.

Nem todas as empresas estão no mesmo nível de maturidade em gerenciamento de projetos, elas diferem drasticamente neste quesito, mesmo as empresas que pertencem ao mesmo ramo. Uma gerência de projetos efetiva requer um entendimento claro sobre o posicionamento da empresa em termos de maturidade e quais ações devem executar para seguir adiante. $\mathrm{O}$ entendimento sobre a maturidade do nível de projeto de uma organização se faz necessário uma vez que a forma com que os projetos são conduzidos na organização está diretamente ligada a este aspecto (Pauli \& Sell, 2019).

Os modelos de maturidade em gerenciamento de projetos apresentam-se como ferramentas para auxiliar as organizações no entendimento de seus níveis de competências em gerenciamento de projetos e a estabelecer estratégias para a melhoria contínua, visando atingir os objetivos estratégicos da organização por meio dos projetos (Pereira et al., 2019). Atualmente existem diversos modelos de maturidade em gerenciamento de projetos conhecidos, porém os mais difundidos são: Capability Maturity Model Integration (CMMI), Project Management Maturity Model (PMMM), Organizational Project Management Maturity Model (OPM3) e o Modelo de Maturidade de Gerenciamento de Projetos (MMGP) (Souza \& Gomes, 2015).

O modelo CMMI foi desenvolvido em 1986 pelo Software Engineering Institute (SEI) da Carnegie Mellon University, nos Estados Unidos, como meio de aprimorar a capacidade das empresas no desenvolvimento de software. Foi um dos primeiros modelos a utilizar o gerenciamento de projetos em sua estrutura (Kolotelo, 2008). A construção deste modelo envolveu uma grande quantidade de pessoas de diferentes organizações em todo o mundo e busca a melhoria dos processos de desenvolvimento de software. O seu principal objetivo é fornecer direcionadores para melhorar os processos da empresa e sua capacidade de gerenciar o desenvolvimento, aquisição e manutenção de produtos e serviços.

Dentro dos níveis de maturidade do CMMI, são identificadas as metas específicas e genéricas que devem ser alcançadas pelos processos de planejamento e implementação da organização, que são essenciais para o atingimento dos níveis de maturidade. A satisfação das metas é utilizada em avaliações, como base para atendimento das áreas de processo e determinação do nível de maturidade da organização. É considerada uma metodologia impulsionada por metaschave que a organização deve perseguir e compará-las ao (Quintella \& Rocha, 2005).

O MMGP foi criado por Darci Prado (2002), este é um modelo que pode ser aplicado tanto em setores da empresa quanto no ambiente corporativo como um todo e contempla níveis, elementos e dimensões. Os cinco níveis retratam a capacidade da organização em se articular para atender aos objetivos estratégicos e correlacionam-se com elementos em diferentes intensidades. Estes elementos são seis, a saber: competências técnicas, metodologia, informatização, estrutura organizacional, competências comportamentais e contextuais (Campos et al., 2020).

Campos et al. (2020) ainda acrescentam que a avaliação do nível de maturidade de uma organização ou setor pode ser feita através da aplicação de um questionário de 40 questões. Através das respostas é possível calcular o nível de maturidade setorial ou corporativo de uma organização.

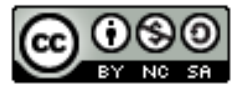


Citação (APA): Bonato, S. V., Gandin, F. F., Ribeiro, L. M., \& Pereira Junior, E. F. Z. (2021). Escritório de gerenciamento de projetos: proposta para uma empresa do ramo industrial de rodovias e extração de minério. Brazilian Journal of Production Engineering, 7(2), 111-127.

Com objetivo de criar um modelo de maturidade em gerenciamento de projetos alinhado às metodologias-padrão do PMI é que foi constituído, em 2004, o programa Organizational Project Management Maturity Model (OPM3 ${ }^{\mathrm{TM}}$ ). O OPM3 foi desenvolvido no sistema de voluntariado e constituído pela incorporação de resultados de diversas pesquisas sobre as melhores práticas aderentes às necessidades de gerenciamento de projetos identificadas em vários países (Pereira et al., 2019).

O modelo OPM3 é formado por três domínios: projeto, programa, portfólio; quatro estágios de melhoria de processo (padronização, medição, controle e melhoria contínua); e três elementos básicos que compõem o ciclo para implantação: conhecimento, avaliação e melhoria (Campos et al., 2020).

O modelo PMMM foi desenvolvido por Kerzner em 2005 e busca a aplicação prática da gestão de mudança, na qual se procura minimizar a resistência na implantação do sistema de gerenciamento de projetos, através da disseminação da cultura e orienta seu planejamento. $\mathrm{O}$ modelo PMMM define o estágio atual da empresa, o planejamento, ações para implantação e desenvolvimento gradual da gerência de projetos (Campos et al., 2020).

Neste modelo o autor reforça a necessidade de um plano e a curva de aprendizado é medida em anos. A cultura da organização e a natureza do negócio é que irão determinar o tempo gasto no desenvolvimento de cada uma das cinco fases do ciclo de vida para a maturidade.

O modelo PMMM possui um questionário de 183 questões distribuídas conforme o nível, sendo 80 questões para o nível 1, 20 questões para o nível 2, 42 questões para o nível 3, 25 questões para o nível 4 e, 16 questões para o nível 5 (Campos et al., 2020).

\subsection{Escritório de Projetos}

Na medida em que gerenciar projetos está cada vez mais presente como forma de viabilizar as estratégias das organizações, a necessidade de centralizar e controlar as informações dos portfólios dos projetos torna-se fundamental para a condução deles. Os escritórios de gerenciamento de projetos ou Project Management Office (PMO) surgiram mediante esta necessidade (Bonato et al., 2020).

Atualmente PMO possui diversas definições, sendo que a maioria delas associa o escritório à fonte das melhores práticas de gerenciamento de projetos, constituindo-se desta forma como o responsável por implementar, manter e suprir as necessidades da organização no quesito gerenciamento de projetos (Ferreira \& Philyppis Junior, 2019).

A busca pela excelência em gerenciamento de projetos é o fator que normalmente conduz à decisão de implementação de um escritório de gerenciamento de projetos, no entanto, é importante que sejam consideradas diversas variáveis, dentre as quais a principal delas é o nível de maturidade no qual a empresa se encontra (Pauli \& Sell, 2019).

Ferreira e Philyppis Junior (2019), explicam que os escritórios de projetos podem ser classificados em três níveis diferentes, sendo eles: Nível 1 - Escritório de Controle de Projetos: possui como principais funções o desenvolvimento do planejamento do projeto e a emissão de relatórios de progresso. Apresenta foco em um único projeto, porém de grande porte e complexidade; Nível 2 - Escritório de Projetos da Unidade de Negócios: oferece suporte aos 
Citação (APA): Bonato, S. V., Gandin, F. F., Ribeiro, L. M., \& Pereira Junior, E. F. Z. (2021). Escritório de gerenciamento de projetos: proposta para uma empresa do ramo industrial de rodovias e extração de minério. Brazilian Journal of Production Engineering, 7(2), 111-127.

projetos da área, de diferentes porte e complexidade. As principais funções do escritório de gerenciamento de projetos são a priorização entre os projetos e o gerenciamento de recursos, no entanto, a integração destes projetos ocorre ao nível da unidade de negócios, não atingindo o nível corporativo; e Nível 3 - Escritório Estratégico de Projetos: as principais atribuições do escritório de gerenciamento de projetos deste nível são: selecionar, priorizar e garantir a integração dos projetos de forma que estejam alinhados à estratégia da organização, inclusive no que se refere ao uso de recursos; desenvolver, atualizar e divulgar a metodologia de gerenciamento de projetos, bem como divulgar o conhecimento em gerenciamento de projetos; tornar-se um centro de gestão do conhecimento, através do armazenamento de informações dos projetos na forma de lições aprendidas; validar as estimativas de recursos feitas pelos projetos, baseado nas experiências de projetos anteriores.

\section{Procedimentos Metodológicos}

Quanto à natureza da pesquisa, este trabalho é uma pesquisa descritiva, pois configura-se como um estudo intermediário entre a pesquisa exploratória e a explicativa. Não é tão preliminar quanto a primeira nem tão aprofundada quanto a segunda. A pesquisa descritiva é desenvolvida por meio de técnicas padronizadas de coleta de dados como questionário e observação sistemática (Roesch, 2015). Tem como objetivo principal a descrição das características de determinada população ou fenômeno ou o estabelecimento da relação entre as variáveis (Gil, 2018).

Esta pesquisa será composta por dois tipos de procedimentos, sendo o primeiro o levantamento de campo (survey), através do qual será realizada a solicitação de informações diretas de pessoas específicas, cujo comportamento se deseja conhecer. Os dados coletados serão submetidos a análise quantitativa para obter-se as conclusões para composição do trabalho (Gil, 2018). O segundo procedimento utilizado na composição da pesquisa será o estudo de caso, pois é o tipo de pesquisa que se dedica a estudos do passado, presente e interações ambientais de uma unidade. É uma pesquisa onde o caso não é fragmentado, pois todas as unidades estão inter relacionadas e baseia-se em uma variedade de fontes de informação (Roesch, 2015).

Para realização desta pesquisa serão utilizadas duas formas de abordagem. Segundo Roesch (2015), a integração da pesquisa quantitativa e qualitativa permite ao pesquisador o cruzamento de suas conclusões, maximizando a amplitude na descrição, explicação e compreensão do objeto de estudo.

Conforme Roesch (2015) a pesquisa qualitativa é aquela em que se pode traduzir em números as opiniões e informações e, classificá-las e analisá-las. Ela tem o intuito de garantir resultados e evitar distorções de análise e interpretação (Roesch, 2015). Uma vez que para a coleta de dados deste trabalho será utilizado um questionário, a forma de abordagem quantitativa será aplicada. Dentro desta mesma pesquisa haverá a análise de um ou mais processos e seu significado, onde Roesch (2015) afirma que a interpretação dos fenômenos e a atribuição dos significados são características básicas do processo de pesquisa qualitativa. Para Roesch (2015) a pesquisa qualitativa garante a riqueza dos dados e permite ver um fenômeno na sua totalidade, além de facilitar a exploração de contradições e paradoxos. Diante destes conceitos, pode-se confirmar que as duas formas de abordagem serão utilizadas.

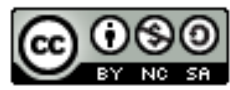


Citação (APA): Bonato, S. V., Gandin, F. F., Ribeiro, L. M., \& Pereira Junior, E. F. Z. (2021). Escritório de gerenciamento de projetos: proposta para uma empresa do ramo industrial de rodovias e extração de minério. Brazilian Journal of Production Engineering, 7(2), 111-127.

A coleta de dados para esta pesquisa se deu de duas formas, sendo a primeira através da aplicação de um questionário para avaliação do nível de maturidade da empresa em gerenciamento de projetos e a segunda, através da análise de arquivos disponibilizados pela empresa.

Os colaboradores selecionados para responderem ao questionário são pessoas ligadas diretamente a elaboração do planejamento estratégico da empresa, responsáveis pela definição e condução dos projetos de negócio da empresa. O questionário aplicado foi composto por 40 questões extraídas do "Questionário de Avaliação de Maturidade (MMGP)" do autor Darci Prado, conforme descrito no referencial teórico. As questões são de múltipla escolha e estão divididas em 4 módulos: conhecido, padronizado, gerenciado e otimizado. Todas as perguntas eram obrigatórias e possibilitavam a seleção de apenas uma resposta. $\mathrm{O}$ questionário foi publicado na ferramenta Google Docs e um link de acesso enviado ao público alvo.

A segunda forma de coleta de dados se deu através da consulta a documentos de histórico dos projetos de negócio, tais como: documentos de portfólio de projetos, cronogramas, fluxos de processos, planos preliminares de projetos e planos detalhados de projeto. Foram analisados também organogramas da empresa, organogramas setoriais e o macro fluxo dos processos de negócio da empresa.

A análise dos dados obtidos através do questionário foi feita mediante a exportação dos mesmos para a ferramenta Microsoft Excel ${ }^{\circledR}$, onde cada questão recebeu o peso conforme a metodologia MMGP. Após calcular os pontos obtidos de cada área, foi possível chegar à média de pontos da organização e medir o perfil de aderência da empresa à gestão de projetos e, consequentemente, identificar o nível de maturidade em gestão de projetos no qual a empresa se encontra.

\section{RESUltados E Discussão}

\subsection{APRESENTAÇão da ORGanizaÇão}

A empresa é membro de um grupo alemão, que é composto por cinco empresas que fabricam e comercializam máquinas para pavimentação de rodovias e máquinas para extração de minério. Três empresas estão instaladas na Alemanha, uma na China e a empresa instalada no Brasil. O grupo está presente em 181 países com 55 escritórios de vendas e serviços e mais de 100 representantes autorizados, distribuídos em todos os continentes. Possui mais de 4.500 colaboradores e o seu faturamento anual supera 1,5 bilhões de Euros.

A empresa escolhida para o desenvolvimento desta pesquisa, foi fundada em 1958 e está situada na cidade de Porto Alegre em uma área de $48.000 \mathrm{~m}^{2}$ quadrados. Conta atualmente com 380 colaboradores, divididos entre a fábrica em Porto Alegre e suas filiais, instaladas nos estados de Pernambuco, Goiás e Rio de Janeiro. É a empresa do grupo especialista e exclusiva na fabricação de usinas de asfalto, responsável também pela fabricação de modelos de vibro acabadoras com características diferenciadas, cujo propósito é o de atender ao mercado brasileiro e demais países da América Latina. Possui ainda, o licenciamento para fabricação e comercialização de produtos das demais empresas do grupo, tais como, fresadoras, recicladoras

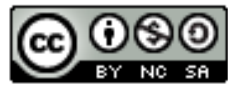


Citação (APA): Bonato, S. V., Gandin, F. F., Ribeiro, L. M., \& Pereira Junior, E. F. Z. (2021). Escritório de gerenciamento de projetos: proposta para uma empresa do ramo industrial de rodovias e extração de minério. Brazilian Journal of Production Engineering, 7(2), 111-127.

e rolos compactadores. A comercialização destes produtos gera uma receita média de 116 milhões de euros anuais.

Na sua sede em Porto Alegre está instalada toda sua capacidade fabril e o desenvolvimento de novos produtos. Os projetos de novas máquinas são desenvolvidos em Porto Alegre e informações de tecnologia e projetos de engenharia são compartilhados com a área de desenvolvimento de produto de sua matriz, na Alemanha.

Atualmente a empresa possui dois diretores que compartilham as responsabilidades e decisões estratégicas da empresa. Ambos respondem diretamente aos proprietários do grupo, na Alemanha. O diretor presidente é responsável pela área industrial, tecnologia da informação e recursos humanos, e o diretor comercial responsável pelas atividades comerciais da matriz e filiais, além das áreas financeiras e jurídica.

\subsection{ORIGEM dos Projetos}

O planejamento estratégico da empresa é elaborado considerando um horizonte de 5 anos. Participam deste processo diretores, gerentes e coordenadores e, tem como resultado as metas a serem atingidas para este período. Como forma de viabilizar o planejamento traçado, as ações são segmentadas em projetos de negócio, que devem ser executados individualmente.

Ao final deste processo uma lista de aproximadamente 30 projetos é formada e deve ser submetida para aprovação da matriz na Alemanha, para tanto, cada gestor deve relacionar o projeto específico ao objetivo estratégico traçado pela empresa, assim como, elaborar uma estimativa de gastos que serão envolvidos em cada um dos projetos. Estes dados serão consolidados pela área de controladoria e serão analisados previamente pela diretoria da empresa. Após aprovação da diretoria, o portfólio de projetos é discutido junto à matriz na Alemanha. A análise e aprovação dos projetos ocorrem no mês de outubro de cada ano e as verbas aprovadas para sua execução ficarão disponíveis a partir do mês de janeiro do próximo ano.

Uma vez que o ano inicia, os projetos que foram aprovados deverão ser operacionalizados, para tanto, as equipes deverão ser preparadas e organizadas, os fornecedores de serviço deverão ser contratados, ferramentas e materiais adquiridos, enfim, todo o planejamento específico que um projeto exige deve ser providenciado para que este seja desenvolvido. É neste momento que a empresa enfrenta uma grande dificuldade, pois não há uma área específica para gerenciamento do portfólio de projetos. A diretoria da empresa entende que cada área de negócio é responsável pela gestão e execução de cada um de seus projetos, no entanto, os gestores têm dificuldades em entender o conceito e a metodologia de gerenciamento de projetos. Muitos gestores participaram de projetos como recursos, porém nunca gerenciaram um projeto.

Conforme dados fornecidos pela área de controladoria da empresa, os projetos de negócio aprovados para o ano somaram $\mathrm{R} \$ 5.500 .000,00$. Considerando que o faturamento estimado para o mesmo ano é de $\mathrm{R} \$ 310.000 .000,00$ e o lucro líquido estimado em torno de 3,85\%, o lucro líquido somaria $\mathrm{R} \$ 11.935 .000,00$. Deste lucro, 46,08\% foi reservado para investimento na empresa através de projetos de negócio ou tecnologia.

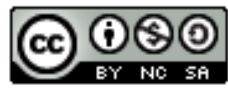



uma empresa do ramo industrial de rodovias e extração de minério. Brazilian Journal of Production Engineering, 7(2), 111-127.

\subsection{Nível de Maturidade em Gestão de Projetos - Diagnóstico}

Devido a quantidade de projetos desenvolvidos pela empresa a cada ano e o volume de investimentos aplicados nestes projetos, a necessidade de gerenciá-los de forma eficiente, manter os prazos e custos previstos é um fator fundamental para o sucesso do negócio. Apesar da alta administração da empresa entender que os gestores possuem os conhecimentos e habilidades necessárias para a condução dos projetos de suas áreas, grande parte dos projetos aprovados para execução durante o ano não são finalizados com sucesso, pois não cumprem os prazos planejados, não cumprem o orçamento aprovado ou até mesmo por não serem sequer iniciados, desperdiçando a verba pré-aprovada, prejudicando a imagem da gestão da empresa perante sua matriz.

Medir o nível de maturidade em gerenciamento de projetos da empresa tem como objetivo conhecer o nível de entendimento e aplicação da metodologia de gerenciamento de projetos que a empresa tem atualmente. Esta pesquisa busca, através de seu resultado mostrar as áreas da empresa que necessitam de maior investimento em treinamento e maior acompanhamento de pessoal especializado. Terá como objetivo contribuir com a consolidação da necessidade de uma área específica para gerenciamento, acompanhamento e alinhamento dos projetos operacionais à estratégia da empresa.

Durante esta pesquisa diversas metodologias de avaliação de maturidade em gestão de projetos foram estudas e as principais descritas no referencial teórico deste trabalho. Ao analisar as características de cada uma delas, considerando as particularidades da empresa pesquisada e $o$ tempo para o desenvolvimento deste trabalho, a metodologia que mais se adequou a este processo foi a MMGP, uma vez que a "dimensão" alinhamento estratégico é o foco principal desta metodologia, vindo ao encontro a uma das funções principais dos projetos - alinhamento à estratégia empresarial - outra característica importante desta metodologia é possuir uma linguagem simples e comum a qualquer área de negócio, sendo possível que pessoas que não possuem conhecimentos específicos em gerenciamento de projetos possam compreender as perguntas e responder de forma adequada, além de conter uma quantidade de questões razoável para serem respondidas pelos gestores da empresa.

Conforme descrito nos procedimentos metodológicos deste trabalho, foi realizada a aplicação do questionário de acordo com a metodologia MMGP. Para aplicação deste, foi solicitada autorização prévia ao diretor presidente da empresa o objetivo do estudo e as questões apresentadas.

Esta pesquisa teve como objetivo estabelecer o nível de maturidade da empresa, portanto, foi determinado que ao responder as 40 questões, os 2 diretores estavam avaliando o nível de maturidade da organização como um todo, enquanto que ao responder cada uma das 40 questões, cada gerente estava avaliando sua área específica, por exemplo, o gerente de marketing ao responder as questões estava avaliando o nível de maturidade em gestão de projetos da área de marketing.

Para responder ao questionário foram selecionados os colaboradores que atuam diretamente na elaboração do planejamento estratégico. No quadro 1 estão descritos os cargos, tempo de 

uma empresa do ramo industrial de rodovias e extração de minério. Brazilian Journal of Production Engineering, 7(2), 111-127.

empresa e experiência em projetos que cada um apresentava até a data de fechamento deste trabalho.

\begin{tabular}{|c|c|c|}
\hline \multicolumn{2}{|c|}{ Quadro 1. Entrevistados na empresa } \\
\hline CARGO & $\begin{array}{c}\text { TEMPO DE } \\
\text { EMPRESA }\end{array}$ & $\begin{array}{c}\text { EXPERIÊNCIA EM } \\
\text { PROJETOS }\end{array}$ \\
\hline Diretor Comercial & 4 anos & GP, ME \\
\hline Diretor Presidente & 2 anos & GP, ME \\
\hline Gerente de Marketing & 2 anos & ME \\
\hline Gerente de Vendas & 5 anos & ME \\
\hline Gerente de Serviços & 3 anos & GP, ME \\
\hline Controler & 2 anos & GP, ME \\
\hline Gerente de TI e Processos & 2 anos & GP, ME \\
\hline Gerente de RH & 2 anos & ME \\
\hline Gerente de Produto & 16 anos & GP, ME \\
\hline Gerente de P\&D & 6 anos & GP, ME \\
\hline Gerente de PCP e Supply Chain & 3 anos & ME \\
\hline
\end{tabular}

* GP: Gerente de Projetos

* Membro da Equipe de Projetos

Fonte: Autores

Conforme definido na metodologia MMGP, cada grupo de questões corresponde a um nível, sendo assim, foi realizado o somatório dos pontos obtidos em cada grupo de questões e o perfil de aderência da empresa à metodologia de gerenciamento de projetos foi montado, conforme exibido no quadro 2 .

Quadro 2. Perfil de aderência da empresa conforme MMGP

\begin{tabular}{|c|c|c|c|c|c|c|c|c|c|c|c|}
\hline \multirow{2}{*}{ Nível } & \multirow{2}{*}{ Pontos Obtidos } & \multicolumn{10}{|c|}{ Perfil Aderência } \\
\hline & & 10 & 20 & 30 & 40 & 50 & 60 & 70 & 80 & 90 & 100 \\
\hline 2 & 48 & & & & & & & & & & \\
\hline 3 & 31 & & & & & & & & & & \\
\hline 4 & 14 & & & & & & & & & & \\
\hline 5 & 7 & & & & & & & & & & \\
\hline
\end{tabular}

Fonte: Adaptado de Campos et al. (2020)

Ao analisar os dados apresentados no quadro 2 pode-se observar que o nível de aderência da empresa à metodologia de gerenciamento de projetos é baixo (Nível 2 - Conhecido), representando um grande potencial e necessidade de crescimento.

A diretoria entende que a empresa está no nível 3 de maturidade, remetendo a uma empresa onde já existe padronização, procedimentos definidos e exige-se um nível de comprometimento maior dos envolvidos nos projetos. No entanto, através das respostas fornecidas pela gerência das áreas operacionais, a empresa possui uma aderência baixa, pois classifica-se no nível 2, onde os esforços para condução dos projetos ocorrem em áreas isoladas, os treinamentos não são disseminados e grande parte dos projetos não são bem-sucedidos ou são concluídos baseados em esforços individuais.

Desta forma, pode-se identificar a primeira dificuldade na operacionalização dos projetos na organização, não há alinhamento entre as expectativas da diretoria sobre a condução dos projetos e a real condição dos gestores em desempenhar este papel. As áreas de negócio não 

uma empresa do ramo industrial de rodovias e extração de minério. Brazilian Journal of Production Engineering, 7(2), 111-127.

possuem o preparo necessário para acompanhamento e execução dos projetos e a empresa não têm ações relevantes no sentido de preparar as equipes para condução dos projetos de forma adequada.

\subsection{Projetos Conduzidos Com Metodologia de Gerenciamento E SEM Metodologia de Gerenciamento de Projetos}

O projeto Fluxo de Materiais teve como objetivo aumentar a acuracidade das informações dos estoques no sistema ERP da empresa, assim como, estabelecer maior controle físico dos itens dentro do armazém central dela. Este projeto envolveu mudanças no sistema ERP, assim como, investimentos e redefinições de layout e instalações físicas no armazém de abastecimento central da fábrica. No quadro 3 serão apresentados dados deste projeto.

Quadro 3. Dados do projeto fluxo de materiais

\begin{tabular}{|c|c|c|c|c|}
\hline $\begin{array}{c}\text { Período do } \\
\text { Projeto }\end{array}$ & $\begin{array}{c}\text { Responsável } \\
\text { pelo Projeto } \\
\text { (Sponsor) }\end{array}$ & $\begin{array}{c}\text { Gerente do } \\
\text { Projeto }\end{array}$ & $\begin{array}{c}\text { Valor do } \\
\text { Investimento }\end{array}$ & Equipe do Projeto \\
\hline $\begin{array}{c}\text { Início: } \\
\text { Outubro/2019 } \\
\text { Final: } \\
\text { Janeiro/2020 } \\
\text { *Prazo } \\
\text { Cumprido }\end{array}$ & $\begin{array}{c}\text { Diretor } \\
\text { Presidente }\end{array}$ & $\begin{array}{c}\text { Analista de } \\
\text { negócio }(\mathrm{TI})\end{array}$ & $\begin{array}{c}\mathrm{R} \$ 68.000,00 \\
* \text { Orçamento } \\
\text { Cumprido }\end{array}$ & $\begin{array}{c}\text { 01 Analista de negócio (TI) } \\
01 \text { Especialista em PCP } \\
01 \text { Analista de Materiais } \\
\text { 01 Consultor externo ERP } \\
01 \text { Gerente de PCP e Materiais } \\
\text { 01 Coordenador de PCP } \\
\text { 01 Diretor presidente } \\
\text { 01 Controler }\end{array}$ \\
\hline
\end{tabular}

Fonte: Autores.

Neste projeto não houve mudanças de escopo, as alterações solicitadas foram atendidas na fase 2 do projeto. A data de entrega ocorreu conforme planejado. Após a implementação do projeto foram realizadas reuniões de acompanhamento. Uma após a primeira semana de operação e a segunda após 30 dias, onde o projeto foi dado por encerrado com sucesso pela equipe de projeto.

O projeto Recebimento Eletrônico teve como objetivo aumentar a velocidade no recebimento de materiais, realizar a validação dos dados dos arquivos XML enviados pelos fornecedores em relação aos pedidos de compra e atender aos requisitos da legislação federal quanto ao armazenamento dos arquivos eletrônicos. No quadro 4 serão apresentados dados deste projeto.

Quadro 4. Dados do projeto recebimento eletrônico

\begin{tabular}{|c|c|c|c|c|}
\hline $\begin{array}{l}\text { Período do } \\
\text { Projeto } \\
\end{array}$ & $\begin{array}{l}\text { Responsável pelo } \\
\text { Projeto (Sponsor) }\end{array}$ & $\begin{array}{l}\text { Gerente do } \\
\text { Projeto }\end{array}$ & $\begin{array}{c}\text { Valor do } \\
\text { Investimento } \\
\end{array}$ & Equipe do Projeto \\
\hline $\begin{array}{l}\text { Início: Julho/2019 } \\
\text { Final: } \\
\text { Setembro/2019 } \\
\text { *Ultrapassou em } 48 \\
\text { dias úteis o } \\
\text { planejamento }\end{array}$ & Contador & $\begin{array}{l}\text { Analista de } \\
\text { negócio (TI) }\end{array}$ & $\begin{array}{c}\mathrm{R} \$ 90.000,00 \\
* \text { Ultrapassou } \\
\text { em } \\
\mathrm{R} \$ 97.000,00 \text { o } \\
\text { planejamento }\end{array}$ & $\begin{array}{c}\text { 01 Analista de negócio (TI) } \\
\text { 01 Analista Fiscal } \\
\text { 01 Assistente Fiscal } \\
01 \text { Assistente de Compras } \\
01 \text { Assistente de Materiais } \\
\text { 01 Contador } \\
\text { 01 Coordenador de Compras } \\
\text { 01 Gerente de Compras } \\
\text { 01 Coordenador de Logística } \\
\text { 01 Controler } \\
\text { 01 Consultor externo ERP }\end{array}$ \\
\hline
\end{tabular}

Fonte: Autores.

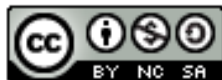


Citação (APA): Bonato, S. V., Gandin, F. F., Ribeiro, L. M., \& Pereira Junior, E. F. Z. (2021). Escritório de gerenciamento de projetos: proposta para uma empresa do ramo industrial de rodovias e extração de minério. Brazilian Journal of Production Engineering, 7(2), 111-127.

Algumas atividades que apresentaram falhas ou que não foram executadas e que implicaram no atraso das entregas, entregas com baixa qualidade, trabalho manual e grande impacto negativo nas operações diárias da empresa. Estas falhas resultaram em atraso de 48 dias úteis no projeto e um acréscimo de $107 \%$ no custo final do projeto.

\subsection{Modelo de Escritório de Projetos Sugerido}

Como meio de apoiar a diretoria da organização na operacionalização dos projetos de negócio, de forma a mantê-los alinhados à estratégia da empresa e, principalmente, suportar os gestores das áreas operacionais quanto ao desenvolvimento dos projetos, sugere-se um modelo de escritório de gerenciamento de projetos aderente a estrutura da empresa.

A sugestão de implementação de um escritório de gerenciamento de projetos está baseada na necessidade que a empresa apresenta quanto ao controle do portfólio de seus projetos. Com base na literatura estudada, pode-se afirmar que não existe uma fórmula única para implementação nem mesmo um único modelo de escritório de gerenciamento de projetos. Cada organização pode desenvolver uma configuração específica de escritório de gerenciamento de projetos, baseado em suas características, recursos e conhecimento.

A implementação do escritório de gerenciamento de projetos vai além da organização de um grupo de pessoas para auxiliar no controle de cronogramas e documentos de projetos, trata da criação de um novo departamento na empresa, que fará parte do organograma funcional e terá suas responsabilidades bem definidas dentro da organização. Terá como objetivo estratégico inserir na cultura da empresa a metodologia de gerenciamento de projetos.

Devido a necessidade de alinhamento dos projetos de negócio à estratégia da empresa, entendese que o responsável pelo escritório de projetos (Gerente do Escritório de Projetos) deverá fazer parte do grupo de gestores que participa da elaboração e definição do planejamento estratégico da empresa. Os responsáveis pelos projetos continuarão sendo os gestores das áreas, porém, o escritório de gerenciamento de projetos deverá ser a estrutura que suportará os gestores e suas equipes no planejamento, controle e execução de cada um dos projetos.

O primeiro ano de implantação do escritório de gerenciamento de projetos deve ser tomado como base para avaliação do desempenho alcançado e ajustes para atender às necessidades da empresa, portanto, inicialmente o escritório de gerenciamento de projetos deverá atuar nos projetos de mudanças em processos já implementados no ERP da empresa, implantação de novos sistemas de TI e melhorias em sistemas corporativos. Com base na demanda atual de projetos de sistemas que a empresa apresenta, recomenda-se que a estrutura do escritório de gerenciamento de projetos seja composta no primeiro ano por um gestor responsável pela área e dois analistas de projetos.

Quanto a definição das responsabilidades: (i) Gerente do escritório de projetos: deverá participar do planejamento estratégico e gerenciar o escritório de gerenciamento de projetos como uma nova área da organização. Acompanhar os indicadores, desenvolver padrões de documentação e treinar os colaboradores na metodologia de gerenciamento de projetos; (ii) Analista de projetos I: Será responsável pelo controle e execução dos projetos de manufatura, logística, compras, vendas, serviços e engenharias; e (iii) Analista de projetos II: Será responsável pelo controle e execução dos projetos de finanças e obrigações legais. 
Citação (APA): Bonato, S. V., Gandin, F. F., Ribeiro, L. M., \& Pereira Junior, E. F. Z. (2021). Escritório de gerenciamento de projetos: proposta para uma empresa do ramo industrial de rodovias e extração de minério. Brazilian Journal of Production Engineering, 7(2), 111-127.

As equipes que trabalharão na execução dos projetos não terão dedicação integral a esta atividade, sendo requisitadas de acordo com o cronograma de cada um dos projetos. Esta configuração de trabalho caracteriza uma organização funcional. Sugere-se a implantação nesse formato para que a empresa faça adaptação gradual ao novo método de trabalho.

\section{CONSIDERAÇões Finais}

Os projetos de negócio da empresa são oriundos do planejamento estratégico, ou seja, os projetos operacionalizam as estratégias traçadas pela diretoria da empresa. Os investimentos em projetos de negócio no ano foram aprovados com base na lucratividade estimada para o ano, sendo que 46,08\% do lucro líquido foi revertido em projetos. Considerando este percentual, entende-se que a empresa deve reavaliar o método de controle atual de seus projetos, de forma que possa melhorar o aproveitamento de seus recursos.

Para que fosse possível identificar o nível de conhecimento em gerenciamento de projetos que a empresa se encontra atualmente, foi aplicada a pesquisa de nível de maturidade, onde foi encontrada a primeira evidência da dificuldade na gestão adequada dos projetos da empresa. Através desta pesquisa foi constatado que a diretoria da organização entende que ela está em um nível mais elevado do que os demais gestores de área, ou seja, a diretoria deposita mais responsabilidades aos gerentes quanto ao planejamento, execução e controle dos projetos do que eles e suas equipes efetivamente estão preparados para desempenhar.

Como segundo ponto de análise, foi realizada a comparação entre 2 projetos executados na empresa no ano, onde foi avaliada a aplicação dos grupos de processos de gerenciamento de projetos e áreas de conhecimento. Ambos os projetos tiveram como figura do gerente de projeto um analista de TI, no entanto, no primeiro projeto o analista recebeu autonomia para condução das atividades de acordo com a metodologia de gerenciamento de projeto e as atividades ocorreram conforme o planejado. Já no segundo projeto o analista realizou apenas as atividades de comunicação, não teve autonomia para gerenciar o projeto de acordo com a metodologia e, principalmente, não pode inibir as várias alterações de escopo que foram aprovadas durante a execução do mesmo. Diante da comparação apresentada, foi possível identificar o quanto a empresa perdeu na execução inadequada do segundo projeto, onde o custo ultrapassou em 107\% e o prazo em 48 dias úteis do planejado.

Durante o desenvolvimento desta pesquisa diversos artigos e publicações específicas da área de gestão de projetos foram estudados, proporcionando maior conhecimento quanto às principais metodologias de avaliação de maturidade em gerenciamento de projetos presentes no mercado. Diante das características de cada uma das metodologias, comparadas com as características da metodologia MMGP foi escolhida como a mais aderente para compor este trabalho. A metodologia MMGP tem seu foco voltado para o alinhamento estratégico entre projetos e objetivos da empresa e este foi o fator determinante para aplicação desta metodologia na presente pesquisa.

Através da análise dos processos envolvidos para a definição e execução dos projetos, análise das respostas obtidas no questionário da metodologia MMGP em conjunto com o comparativo entre dois projetos realizados na empresa, pode-se concluir que a implantação de um escritório de projetos adequado à estrutura da empresa, trará benefícios concretos para a mesma, 
Citação (APA): Bonato, S. V., Gandin, F. F., Ribeiro, L. M., \& Pereira Junior, E. F. Z. (2021). Escritório de gerenciamento de projetos: proposta para uma empresa do ramo industrial de rodovias e extração de minério. Brazilian Journal of Production Engineering, 7(2), 111-127.

proporcionando um maior controle sobre os investimentos empregados nos projetos de negócio e disseminando o conhecimento em gerenciamento de projetos na empresa como um todo.

Propõe-se que a empresa implemente o escritório de gerenciamento de projetos conforme modelo elaborado nesta pesquisa, cujas características foram baseadas na metodologia MMGP e, realize o acompanhamento das atividades durante o primeiro ano de operação.

Para trabalhos e ações futuras recomenda-se que a empresa realize o acompanhamento das atividades do escritório de gerenciamento de projetos, avalie se o modelo permanece adequado às necessidades de seus processos, estude novas metodologias e implemente melhorias, de forma que o escritório de gerenciamento de projetos tenha condições de aumentar o número de projetos gerenciados, agregando maior valor ao negócio da empresa.

A pesquisa limitou-se a um levantamento do nível de maturidade em gerenciamento de projetos na empresa. Não foram avaliados processos nas demais empresas do grupo ao qual essa faz parte. Os modelos para avaliação do nível de maturidade utilizados são os considerados mais conhecidos e utilizados no meio da gestão de projetos, não abrangendo todos os tipos de modelos existentes atualmente. Para definição do modelo de escritório de projetos não foram feitos levantamentos de viabilidade financeira nem perfil dos funcionários que devem ser contratados ou realocados para atuarem no escritório de gerenciamento de projetos.

\section{REFERÊNCIAS}

Alkhateri, A. S., Abuelhassan, A. E., Khalifa, G. S., Nusari, M., \& Ameen, A. (2018). The Impact of perceived supervisor support on employees turnover intention: The Mediating role of job satisfaction and affective organizational commitment. International Business Management, 12(7), 477-492,

Alves, R. O., Costa, H. G., Quelhas, O. L. G., Silva, L. E. D., \& Pimentel, L. B. (2013). Best practices in project management office implementation: development of success reference. Production, 23(3), 582-594.

Aubry, M., Hobbss, B., \& Thuillier, D. (2007). A new framework for understanding organizational project management through PMO. International Journal of Project Management, 25(4), 328-336.

Bonato, S. V.; Silva, C. C. D. C. D.; Pereira Junior, E. F. Z.; Czarneski, F. R.; \& Ribeiro, L. M. (2020). Public project management office characterization for a brazilian university. Revista Reuna, (25)4, 85-104.

Campos, M. C, Dantas, A. D. B., Milito, C. M., \& Silva, L. S. C. D. (2020). Avaliação de maturidade em gestão de projetos na universidade federal de alagoas utilizando o método Prado-MMGP. Revista de Gestão e Projetos, 11(1), 1-16.

Coimbra, L. A. S., Pereira Junior, E. F. Z., D'avila, L. C., \& Schroeder, E. A. (2019). Fluxo de serviço para mapear falhas: estudo no setor de construção de plataformas petroleiras. Revista do instituto de ciências econômicas, administrativas e contábeis - SINERGIA, 23(2), 47-60.

Evers, G., \& Chappin, M. M. (2020). Knowledge sharing in smart grid pilot projects. Energy Policy, 143(1), 1-24.

Ferreira, D. D. S. L., \& Philyppis Junior. (2019). Gestão de mudanças para implantação de Centro de Serviços Compartilhados em uma empresa de petróleo. Revista de Gestão e Projetos, 10(2) 61-77.

Gil, A. C. (2018). Como elaborar projetos de pesquisa. 6. ed. São Paulo: Atlas. 
Citação (APA): Bonato, S. V., Gandin, F. F., Ribeiro, L. M., \& Pereira Junior, E. F. Z. (2021). Escritório de gerenciamento de projetos: proposta para uma empresa do ramo industrial de rodovias e extração de minério. Brazilian Journal of Production Engineering, 7(2), 111-127.

Irfan, M., Thaheem, M. J., Gabriel, H. F., Malik, M. S. A., \& Nasir, A. R. (2019). Effect of stakeholder's conflicts on project constraints: a tale of the construction industry. International Journal of Conflict Management, 31(4), 1-28.

Kerzner, H. (2003). Strategic planning for a project office. Project Management Journal, 34(2), $13-25$.

Longaray, A. A., Pereira Jr., E. F. Z., Munhoz, R., \& Tondolo, G. (2018). Proposals for redesigning processes and the role of organizational teams: an analysis of scientific production in the light of bibliometrics. Sistemas \& Gestão, 13(2), 246-25.

Lucca, T. A. D., Hinnig, M. P. F., \& Santos, D. (2020). PMO as a tool for the organizational knowledge management: case study in a project-based company of the sanitation service sector. International Journal of Project Management, 4(1), 10-35.

Mota, R. M. B., Fernandes, C. H. D. A., Santos, A. A. R., \& Santos, S. (2019). The conceptual project of a sustainable product: practical experience. Revista de Empreendedorismo $e$ Inovação Sustentáveis, 4(3), 62-74.

Mulcahy, R. (2009). Preparatório para o exame de PMP. EUA: RMC Publications.

Pantoja, H. G., Gonçalves, E. J. B., \& Oliveira, E. de J. (2020). Análise dos estilos de tomada de decisão de egressos dos cursos de engenharia. Brazilian Journal of Production Engineering, 6(3),138-145

Pauli, C., \& Sell, D. (2019). Knowledge Management In Project Management Offices: Diagnosis And Definition Of Strategies For A Private Research Institute. Revista de Gestão e Projetos, 10(3), 47-63.

PMI, P., \& PMI. (2017). Um guia do conhecimento em gerenciamento de projetos (Guia PMBOK). In Project Management Institute (pp. 385-405).

Pereira, F. C. M., Carvalho, R. B. D., \& Ouintão, A. D. A. (2019). Use of competitive intelligence by micro, small and medium-sized enterprises: a case study in the companies associated in Acita, Itabira, Minas Gerais, Brazil. Revista Inteligência Competitiva, 9(3), 100120.

Pereira Junior, E. F. Z, Longaray, A. A. \& Munhoz, R. D. S. (2020). Papel da equipe organizacional no mapeamento de processos de uma secretaria de educação a distância de uma universidade federal. EmRede - Revista de Educação a Distância, 7(1), 21-41.

Pereira Junior, E. F. Z., Schroeder, E. A., \& Dolci, D. B. (2019). Limitações digitais, causas e consequências na efetividade do uso do site trello no planejamento estratégico de uma secretaria de educação a distância de uma universidade federal. EmRede-Revista de Educação a Distância, 6(1), 69-85.

Rego, M. L., \& Silva, T. R. D. (2011) Challenges during a implementation processes of a PMO in a State Government Office. Revista Economia \& Gestão, 11(27), 151-180, 2011.

Roesch, S. M. (2015). Projetos de estágio e de pesquisa em administração: guia para estágios, trabalhos de conclusão, dissertações e estudos de caso. São Paulo: Atlas.

Siqueira, L. D., Crispim, S. F., \& Gaspar, M. A. (2017). The influence of the project management office and the organizational projectized structure in the alignment of information technology projects to business models. Revista Gestão \& Tecnologia, 17(2), 66-92.

Souza, T. F. D., \& Gomes, C. F. S. (2015). Assessment of Maturity in Project Management: A Bibliometric Study of Main Models. Procedia Computer Science, 55(1), 92-101. 